\title{
Citizenship and Health Reform: An Analytical Review of the Politics and Institutional Arrangement of Ghana's National Health Insurance Scheme
}

\author{
${ }^{1}$ Michael Kpessa-Whyte, Ph.D. \\ ${ }^{2}$ Ebenezer Bossman Agyei, Ph.D.
}

\begin{abstract}
Recent studies on health financing reform in Ghana have focused on the institutional legacies and political forces underpinning the dramatic shift from "cash-and-carry" to policy initiatives that find expression in universalism and social inclusion. Yet little attention has been paid to the complex interactions between institutional and ideational elements that account for the policy failure of Ghana's National Health Insurance Scheme (NHIS). Drawing primarily on government records, published books, articles and newspaper publications, we argue that formulating appropriate financial reform strategies requires a proper understanding of how national identities intersect with, and shape the politics, design, and operation of social programs to inform policy outcomes. The article suggests that the sustainability of Ghana's NHIS rests on strategic reform measures including, cost containment, diversified funding and operational arrangement, as well as depoliticization of the health regime.
\end{abstract}

Keywords:Health insurance, health politics, social protection, social citizenship, cost recovery, health financing DOI: $10.7176 /$ PPAR/11-1-05

Publication date: January $31^{\text {st }} 2021$

\section{Introduction}

Good health is one of the most important dimensions of human life, and a very essential determinant of a person's capabilities (Sen 1999, 2002). Indeed, beyond its intrinsic value, health is instrumental in shaping the educational fortunes, employability, cognitive development, income earning abilities, and social status enhancing elements relating to participation in governance, dignity, safety, security and empowerment of the citizenry. Importantly, health care is a critical component of social citizenship and a political symbol that rests on distribution, provision, and access (Béland, Foli, \& Kpessa-Whyte, 2018; Johnson Redden, 2002). The recognition of citizens' entitlement to health care, however, has proven to be an issue that evokes remarkable tension, particularly against the backdrop of fiscal constraint and the need for national integration. This makes necessary an examination of how national identities intersect with, and shape the politics, design, and operation of social programs to inform policy outcomes.

Despite the growing wave of health care reforms in sub-Saharan Africa, there is limited attention to the central role of ideas in policy development and implementation (Béland \& Ridde, 2016). In the context of the present article, it is imperative to understand that health care (as citizenship) is embedded with ideational elements that can provide analytic purchase on the complex nature of health policy making and reform. Drawing theoretical insights from the ideational literature and citizenship discourse, we use Ghana's experience of health care reform to illustrate the complexities surrounding the policy failure of the National Health Insurance Scheme (NHIS). We argue that although the Scheme is broadly understood as a symbol of national identity and has a comparative advantage over the previous cash-and-carry system, it is necessary to examine how health reform strategies and development are shaped by the concept of "nested" factors that challenge the normative premises and sustainability of social programs such as the NHIS. With the advantage of more than a decade since it was introduced and the benefit of hindsight, this study builds on earlier works by Agyepong and Adjei (2008), Seddoh, Adjei, and Nazzar (2011), Giovanni Carbone (2011), Kusi-Ampofo, Church, Conteh and Heinmiller (2015), and Osei-Akoto \& Adamba (2017) on the institutional legacies and political factors that shaped the path-departing and far-reaching shift from cash-and-carry to financing of health care services through health insurance scheme in Ghana.

The role of ideas in the policy process is well established. As most scholars suggest, ideas play a central role in shaping political behaviour and outcomes, and provide a richer understanding of the political and social world (Beland \& Cox, 2011; Fischer, 2003; Schmidt, 2008). While the relationship between ideas and policy implementation is recognized by policy scholars, it has been only recently that the ideas-implementation nexus has been examined in a systematic and detailed manner (Béland \& Ridde, 2016; Ridde, 2009; Schofield, 2001).

\footnotetext{
${ }^{1}$ Michael Kpessa-Whyte, Ph.D. is a Senior Research Fellow with the Institute of African Studies, University of Ghana, Legon. His research interests include social policy, governance, institutional analysis, and democracy and comparative public policy. His previous articles were published in Canadian Journal of African Studies, Ethnic and Racial Studies, Canadian Public Policy, and the International Review of Political Economy among others.

${ }^{2}$ Ebenezer Bossman Agyei, Ph.D. is an Adjunct Faculty with the Department of Political Science, University of Guelph, Ontario, Canada. His research interests include social policy, comparative healthcare politics, governance, development studies, gender and human rights
} 
Perhaps the conception of policy implementation as a simple and straightforward process helps to explain the predominant focus on ideas as relevant to questions about agenda setting. As Mehta (2011) notes, it is important to understand exactly how ideas matter. In a similar vein, Campbell (2002) draws our attention to the discursive marriage between ideas and policy outcomes. The recent work by Béland and Ridde (2016) on health care reform in Africa, for instance, clearly illustrates the potential role of ideas in policy implementation, focusing more generally on the ideas of street-level actors central to the implementation process. In the context of the present study, we examine more broadly how national identities construct citizenship and vice versa, and the complex interplay (and impacts) of context, discourse, and institutional elements central to the design and operation of Ghana's NHIS.

The rest of the paper is organized into six sections. The first section discusses arrangements for financing health care in Ghana prior to the introduction of the NHIS. While in the second section, the paper focuses on the foreground politics that facilitated the introduction of the NHIS; the third section discusses the institutional design of the Scheme. The governance arrangements and the overall operations of the Scheme is the focus of the fourth section of the paper. Section five of the paper analyzed some of the major institutional challenges associated with the health insurance scheme. In concluding, the sixth section shares some ideas on possible options for reforming the scheme to enhance its ability to effectively meets its established objectives.

\section{Health Financing Approaches Prior to NHIS}

Ghana's attainment of independence in 1957 brought with it among others, "'free" health care in public health facilities for the entire citizenry. This consideration meant that there was no direct out-of-pocket payment at the point of consumption of health services in public health facilities. Ghana's immediate post-independence era was thus defined by the idea of social citizenship, and characterized by a system of health financing that guaranteed relatively universal access (Seddoh \& Akor, 2012; Blanchet, Fink, \& Osei-Akoto, 2012). However, this golden age of social welfare was short-lived as sustainability of this form of financing came under serious scrutiny when the economy began to show signs of decline in the face of competing demands on the same source. Gradually, there was a substantial reduction in health spending. It was, however, not after the overthrow of Ghana's first President, Dr. Kwame Nkrumah, that the policy of health financing based on social citizenship began to change. In 1969, when the Progress Party assumed office under the leadership of Dr. Kofi Abrefa Busia, the government introduced hospital user fees to support financing of health care and to minimize abuse of the health system (1969 Hospital Fees Decree). This legislation was later amended to become the Hospital Fees Act of 1971(Act 387) (Carbone, 2011; Nyonator \& Kutzin, 1999).

Ghana was not immune from the global economic upheaval of the 1970s and 1980s, and as the domestic economy began to succumb to the crises (Boafo-Arthur, 1999; Konadu Agyemang, 2001), the military administration of the Provisional National Defence Council (PNDC) was compelled to escalate the financing arrangement as part of the conditionalities of a Structural Adjustment Programme (SAP), that sought to recover

15 percent of recurrent health costs (Agyepong \& Adjei, 2008; Carbone, 2011; Nyonator \& Kutzin, 1999). This cost recovery measure became popularly known in Ghanaian parlance as 'cash-and-carry', which denotes "cash before care" (Kusi-Ampofo et al., 2015, p. 195). Under this system, citizens had to pay for hospital service at the point of service delivery. From an ideational standpoint, the cash-and-carry approach to financing health care was seen as a viable policy response to enhance health delivery and curtail citizenry abuse of the public health system (Asenso-Okyere, Osei-Akoto, Anum, \& Adukonu, 1999; Béland \& Ridde, 2016). However, in a society where large majority of citizens live below the poverty line, the cash-and-carry approach had disastrous effect on the populace (Konadu-Agyemang \& Takyi, 2001). As a pay-per-service policy, by its design, the market approach to health care financing restricted access to healthcare to a few rich individuals who were privileged to afford. As others have argued, most citizens who could not afford the cost of health care turned to self-medication and other cost-saving measures, including increased preference for untested traditional herbal medications (Oppong, 2001; Wahab, 2008). Asenso-Okyere et al. (1999), for instance, observed that healthcare professionals such as nurses, doctors, and other staff in hospitals and health centres in Ghana took advantage of the government's inability to monitor the implementation of the user-fee policy to indulge in imposition of illegal and exorbitant fees for personal gains.

In fact, the deleterious effect of the austerity measures not only entrenched moral hazards (abuse and corruption) and resort to self-medication, but also broadly contributed to a myriad of challenges including the following: dilapidated health infrastructure; understaffed facilities; low pay and low morale; increased health complications and national death toll; and brain drain (Asenso-Okyere, Anum, Osei-Akoto, \& Adukono, 1998; Oppong, 2001; Konadu-Agyemang \& Takyi, 2001). Overall, the health sector was characterized by a downward trajectory, fraught with despair and a sense of a looming socio-political crisis. Indeed, these issues speak to the citizenship narrative and contemporary discourse on the role of the state in nation building (Béland et al., 2018; Johnson Redden, 2002). Importantly, one of the ways by which the citizenry resisted the imposition of the cashand-carry policy was the establishment of community-based health financing schemes based on resource pooling 
and solidarity. As resistance to the cash-and-carry grew, the military government of the PNDC drew inspiration from these community initiatives and began to actively encourage communities and religious organizations "to introduce insurance schemes jointly managed by the facility and the community as a strategy to avoid the problems associated with paying for service at the point of care" (Sulzbach, Garshong, \& Owusu- Banahene, 2005, p. 3).

\section{Politics of the National Health Insurance Scheme}

The costs and hardships imposed on the citizenry by the cash-and-carry approach of the 1980s and the 1990s forced policy makers to initiate a process in search of alternatives for health financing. Realizing the impact of the full cost recovery in the health sector, particularly in an environment of abject poverty, the government initiated a process to replace the policy. In 1985, the first proposal for national health insurance, rooted in an economic liberalization framework, was made after a commission established by the government completed its prefeasibility work (Asenso-Okyere, 1995). This first mover idea was limited in scope as it was intended to provide noncontributory mandatory coverage for civil servants, other formal sector employees, registered cocoa farmers, and an optional premium-based coverage for Ghanaians in the informal sector. Under this arrangement, government was to pay for civil servants, employers for employees and the Ghana Cocoa Board for cocoa famers, and it was suggested the funds for the scheme be privately managed by a Health Insurance Company whose responsibilities, among others, included dispensing ambulatory and hospital services to those covered by the scheme through public and private healthcare providers (Asenso-Okyere, 1995; Osei-Akoto \& Adamba, 2017). Although the idea was seen as a better alternative to the cash-and-carry policy, its implementation could not take off, arguably because the officials of the Ghana Health Service saw the idea of establishing a new company to manage funds meant for financing healthcare as an attempt to outsource their responsibilities to another organization over which they may have no control (Osei-Akoto \& Adamba, 2017).

The return to constitutional rule in 1992 opened a window of opportunity for various policy actors to clamour for change in the country's existing health financing policy. For the political parties, the "crisis" in financing healthcare provided an opportunity to echo the concerns of the citizenry by criticizing the government and proffering what they thought would be the best alternative. For instance, prior to the 1996 presidential and parliamentary elections, the main opposition party, the New Patriotic Party (NPP), chastised the ruling National Democratic Congress (NDC) for what it considered the government's lukewarm attitude towards the crisis facing the health sector and continuous existence of cash-and-carry. Their critique was based on the foregrounding premise that the policy of "cost recovery at the point of service has proven notoriously callous and inhumane" and promised that the system of financing healthcare services will be thoroughly overhauled and the cash-and-carry system reviewed, with a view for evolving a more equitable system including health insurance and other repayment schemes" (NPP Manifesto 1996, 37). The NDC on the other hand, argued that the NPP was being opportunistic in deliberately ignoring initial steps taken by the government towards the introduction of health insurance for all Ghanaians. Against the background of the importance attached to health financing in the elections, following the NDC's victory in the 1996 elections, President Jerry John Rawlings indicated in his State of the Nation address to parliament in 1997 that "this year, a pilot Insurance Scheme will be implemented in Eastern region to test the work done so far. Its performance will be studied, as well as the existing rural health Insurance Schemes so that problems can be identified and eliminated before the implementation can be done on National scale" (Rawlings, 1997).

With the active participation and leadership role of the Ghana Health Service, the government launched pilot health insurance schemes in four districts consisting of New Juaben, Sunhun/kraboa,/Coaltar, South Birim, and South Kwahu in the Eastern Region (Mensah, 2011), following the model of the mutual health insurance scheme initiated by the Catholic Church in Nkoranza in the Brong Ahafo Region ( Mensah, 2011; Sabi, 2005; HeyenPerschorn, 2005). The NDC administration was of the view that the pilot schemes, when allowed to mature, will provide useful lessons for a nationwide rollout of a health insurance scheme, hence must be allowed enough time in operation for the appropriate lessons to be drawn to inform how a nationwide health insurance program could be designed. However, the reality of exclusion and inequity inherent in the cash-and-carry system did not allow for adequate time and reflection on lessons that could be garnered from the pilot schemes. Consequently, in the build-up to the 2000 general elections, health financing became a politically charged policy issue again with all the political parties offering to replace the cash-and-carry policy with an insurance scheme. For instance, during his campaigns toward the 2000 general elections, Dr. Edward Mahama, the Presidential candidate of the People's National Convention Party (PNC) promised to repeal the cash-and-carry policy and replace it with an Americanstyle health insurance program under which the poor and vulnerable will be dependent on government financing (Seddoh, Adjei \& Nazzar, 2011).

Similarly, Dr. Abubakar Al-Hassan, Chairman of the Convention People's Party (CPP), also expressed his party's abhorrence of the cash-and-carry system and pledged the commitment of the CPP to replace it with a health insurance plan for the citizenry. The presidential Candidates for both the National Reform Party (NRP) and the United Ghana Movement (UGM) were also explicit in promising a shift in health financing to an insurance-based approach. As the opposition parties stepped up their criticisms, the government moved further to expand the scope 
of the ongoing health insurance pilots in 2000 to three Districts including Bole, Nkoranza and Dodowa in the Northern, Brong Ahafo and Greater Accra Regions respectively (Seddoh, Adjei \& Nazzar, 2011). The effort by the NDC administration notwithstanding, the party was defeated in the 2000 general elections by the NPP.

Perhaps the NDC was punished at the polls by the electorate because their promised health reform was not as forceful enough, and failed to effectively address the harsh realities of the health environment. Indeed, this development captures how citizens' expectations about health care and state-society relationship has evolved over the years. As Kusi-Ampofo, Church, Conteh, and Heinmiller (2015) note, the NPP, having campaigned with a message of health reform, "was mindful of its promise, fully aware of the dire consequences if it failed to abolish cash-and-carry before the 2004 general election" (p. 207). To be sure, by 2001 when the NPP administration assumed office, several factors had coalesced to firmly place the replacement of the cash-and-carry system with a health insurance program on the policy agenda (Seddoh et al. 2011). Specifically, several policy actors including think tanks, civil society organizations, the media, academics, and transnational actors had built up momentum in anticipation of a nationwide implementation of the health insurance scheme based on the existing experience. Moreover, even though the health financing policy based on the NPP's own ideology required some elements of individual responsibility and choice, the period of the early 2000s was witnessing a shift in the global policy discourse away from strict market fundamentalist dogma to a focus on the social dimensions of development policy that prioritises social protection and poverty reduction (Kpessa-Whyte, 2018). More generally, the political debate and discourse over health financing points to the potential impact of citizenship and ideational factors on policy and development outcomes.

It is striking to note that despite popular support for the idea of health insurance, once the issue arrived on the policy agenda, differences in preference of the type of insurance to be introduced became apparent. For instance, the NPP administration opted to introduce a centrally controlled and managed health insurance fund. However, following from its experience with the piloted district-based health insurance scheme, the NDC argued for the adoption of a decentralized health insurance arrangement that allows every district to own and manage its insurance program (Kusi-Ampofo et al., 2015). This position was supported by the United States Agency for International Development (USAID), whose sponsored research on the matter concluded that "while they [the district mutual health organizations] are not a panacea for resolving health care financing and delivery issues, many of their limitations - small size, limited benefits, and inability to cover all segments of the population, especially the poorest - can be overcome with appropriate design and management" (quoted in Singleton 2006: 25). Other policy entrepreneurs, especially the private insurance companies argued and lobbied for the establishment of legislative arrangement for the operation of purely competitive private health insurance system (Kusi-Ampofo et al., 2015). As evident in the next section, the final structural design of what constitutes health-financing arrangement reflects this divergent design preferences and an attempt to accommodate multiple ideological differences. It goes without saying that the ideological tension or balance between individual responsibility and collective welfare lie at the heart of the citizenship discourse (Johnson Redden, 2002).

\section{Institutional Design of the Health Insurance Scheme}

The NHIS Act, 2003 (Act 650) that established the health insurance scheme provided for the operations of a threetier health financing arrangement consisting of (i) a national health insurance scheme, (ii) community mutual health insurance scheme and (iii) private commercial health insurance scheme. Agyepong \& Adjei (2008) argued that the healthcare financing arrangement established by the policy is "hybrid that comprised a classical single payer scheme for the organized formal sector, and multiple payer semi-autonomous Mutual Health Organizations (MHO) for the non-formal sector. Private commercial health insurance would also be allowed for those who felt they could afford it and preferred it" (p. 155). In its initial design, the first tier, which is known as the National Health Insurance Scheme (NHIS), was structured to operate semi-autonomous District Mutual Health Insurance Schemes (DMHIS) that allow residents in each of the districts in Ghana to join the NHIS through membership registration in a DMHIS. In 2012, the enabling National Health Insurance Act, 2003 (Act 650) was repealed and replaced with the National Health Insurance Act, 2012 to absorb all the DMHIS into one centralized NHIS (National Health Insurance Act, 2012 (Act 852).

According to the NHIS policy, with the exception of the members of the Ghana Armed Forces and the Ghana Police Service, it is mandatory for all persons resident in Ghana to enrol in either the NHIS, community mutual health insurance or undertake a private commercial health insurance plan. While employees in the formal sector have involuntary enrolment by virtue of their contributions through the Social Security and National Insurance Trust (SSNIT) regarding the funding of this tier, informal sector workers and other citizens are required to pay specified annual premium based on income to enrol for coverage into the first tier. The policy granted exemption from payment of premium to a significant number of the citizens, especially elderly persons above 70 years of age, persons below 18 years whose parents are members of the scheme, and others classified as indigent. For the purposes of this policy, the term indigent refers to persons who (a) are unemployed and have no visible means of earning, (b) does not have an easily identifiable place of residence, (c) does not live with a person employed who 
has an identifiable place of residence, and (d) does not have any regular source of support from any person (Witter \& Garshong, 2009; Blanchet, Fink, \& Osei-Akoto, 2012; National Health Insurance Regulations, 2004).

The NHIS derives its funds from eight main sources namely, (a) the National Health Insurance Levy provided for under section 47; (b) two and one half percentage points of each person's contribution to the Basic National Social Security Scheme; (c) moneys that are approved for the Fund by Parliament; (d) moneys that accrue to the Fund from investments made by the Authority; (e) grants, donations, gifts and any other voluntary contributions made to the Fund; (f) fees charged by the Authority in the performance of its functions; (g) contributions made by members of the Scheme; and (h) moneys accruing under section 198 of the Insurance Act, 2006 (Act 724) (National Health Insurance Act, 2012 (Act 852). While the NHIL accounts for about $70 \%$ of the total funds accruing to the scheme, payroll deductions from formal sector workers constitute about $23 \%$. Funds obtained from payment of premium by all residents in Ghana not on formal sector payroll is about $5 \%$ and other funds including returns on investment constitute about two percent. The types of health condition covered by the NHIS is provided for in Legislative instrument 1809 , and this comprise maternity services including caesarean deliveries, emergency services, oral health treatment, out-patient services, most in-patient services, specialist care, most surgeries, general ward accommodation, diagnostic testing and minor operations such as hernia repairs, breast and cervical cancer, and pre-approved list of prescription drugs (National Health Insurance regulations, 2004). The NHIS is said to provide coverage for about 95\% of all ailments that afflict Ghanaians (Witter \& Garshong, 2009; Blanchet, Fink, \& Osei-Akoto, 2012). This scheme, however, does not provide coverage for expensive surgeries, cosmetic surgeries, cancer treatment, kidney dialysis, organ transplant, assisted reproduction, mortuary services, non-listed drugs, HIV retroviral drugs, echocardiogram, photography and physiotherapy, among others (Blanchet, Fink, \& Osei-Akoto 2012; Witter \& Garshong, 2009; National Health Insurance Regulations, 2004).

The second layer of the national health insurance system in Ghana is the community mutual health insurance schemes, which are essentially resource-pooling arrangements for people living in a common locality with the purpose of financing the cost of healthcare for their members. These types of strategic adaptation schemes originated as forms of local citizen's resistance that emerged against the cash-and carry regime when communities began to make contributions into common pool to collectively mitigate the risks associated with the commodification of health services. In a sense, they were illustrations of how the power of the people disempowered the force of public policy by pointing to alternative financing arrangements that ultimately influenced the shift to national health insurance in Ghana. To operate as a community mutual health insurance scheme, the entity must register with, and be licensed by the National Health Insurance Authority (NHIA).

Community-based health insurance schemes, otherwise known as Private Mutual Health Insurance Scheme (PMHIS), exist exclusively for the benefit of their members. Any identifiable group of persons in Ghana who satisfy the requirement of the NHIA, can form and operate this type of health insurance scheme. Members were drawn from people living in a common locality or people sharing similar occupations like farmers, fisher folks, traders, or individuals who share a common religious faith, among others. Companies and business entities are, however, not permitted to enrol their employees in this type of mutual schemes. In other words, the communitybased health insurance schemes were opened to only natural persons as their members and not to corporate institutions. As a membership-based insurance scheme, this layer of the health financing arrangement did not receive any subsidy from the health insurance fund, and so depends solely on the contributions of its membership. Any group of persons that wish to establish community-based mutual health insurance scheme is required to provide proof of at least one million Ghana cedis (GHS 1,000,000.00) of paid-up subscription as initial minimum capital. Prior to the commencement of operations, community-based mutual health insurance schemes are expected to submit a business plan that provides details of the operations, as well as insolvency risks mitigation of the scheme for at least three years to the NHIA (NHIA, 2015a).

Premiums of community-based health insurance schemes are determined by its Board of Directors, who are also responsible for ensuring uniformity in the quality of health services received by members of the scheme. Although independent managers appointed by their Board of Directors manage these types of Schemes, the operations and activities of the scheme are expected to be in compliance with the overarching directives of the NHIA. As part of the rules of the game, every registered community based health insurance scheme is required to set aside $20 \%$ of its minimum capital as reserve fund, which is only available to the scheme on specified conditions in the event of "substantial loss arising from liability to members or providers and the loss cannot reasonably be met from its available resources" or "only in the event of the closure or winding up of the health insurance business for the discharge of the liabilities arising out of policies transacted by the insurer and remaining undischarged at the time of the closure or winding up of the insurance business" (NHIA, 2015-Guidelines). Atim, Grey, Apoya, Anie, \& Aikins (2001) note that successful community-based insurance schemes usually encourage their members to actively participate in the management and decision-making processes as a way of promoting, building social capital, and social learning, the lack of which accounts for the failures of some health insurance schemes. Following recent reforms, this second layer has, however, been collapsed into the centrally managed first tier.

The third layer in the structural design of Ghana's health financing arrangements, which is now the second 
tier by default is also based on an insurance model and referred to as Private Commercial Health Insurance Scheme (PCHIS). These types of health financing schemes operate as business ventures based on market principles. Given that private health insurance entities existed long before the coming into force of the legislations that sought to regularize the health insurance environment in Ghana, this layer is an attempt to accommodate pre-existing private insurance companies financing healthcare, and further liberalize the policy environment to encourage private sector participation. In other words, this type of health insurance is profit-driven and operates on the basis of a rational calculus. As opposed to cross subsidization, this type of health insurance privileges a mechanism based on the calculated risks of particular subscribers. In this regard, subscribers to a private commercial health insurance scheme, which include groups or companies and individuals, are made to pay higher or lower premium based on their classification on the high-low risk continuum. Being schemes run purely as business establishments, they are not entitled to any subsidy from the national health insurance fund (National Health Insurance Act, 2012; NHIA, 2015a). Like the second layer, the management of these types of schemes are also entrusted in the hands of independent managers appointed by their respective Board of Directors. Unlike the second layer, however, the private commercial health insurance schemes are driven primarily by profit for their shareholders.

To qualify as a PCHIS, a company must register with, and be licensed by the NHIA. However, to be licensed, a scheme must show proof of at least five million, five hundred thousand Ghana cedis (GHS 5,500,000) constituting paid-up capital, of which five hundred and fifty thousand Ghana Cedis (GHS 550,000.00) representing $10 \%$ is to be deposited in the Scheme account with the Bank of Ghana as security deposit. This amount is subject to review by the NHIA, and is expected to remain with the Bank of Ghana for as long as the company exists as a health insurance scheme. Private health insurance schemes can make withdrawals from the security deposit subject to an application to and approval by the NHIA. However, approvals for any such withdrawal can only be based on proven knowledge that the scheme had suffered "a substantial loss arising from liability to members or providers and the loss cannot reasonably be met from its available resources" and "the withdrawn amount shall be replaced by the scheme not later than ninety (90) days after the date of withdrawal" (NHIA, 2015a, p. 9). In the event of closure of the business, the security deposit is also made available to the company within the confines of directives by the NHIA. It is instructive to note that beyond the reserve fund and the security deposit, both the community mutual health insurance schemes and the private commercial health insurance schemes were mandated to maintain a contingency fund equivalent of $5 \%$ of net profit or surplus for use in times of crisis (NHIA, 2015). The private health insurance providers only pay for services obtained by their subscribers or members from hospitals and other health institutions that have been duly accredited by the NHIA.

\section{Governance Framework and Operation of the Scheme}

The governance of the health financing system is vested in a NHIA, which in addition to the managerial and administrative responsibility for the national single paper scheme, also doubles as the regulator of the commercial and mutual health insurance scheme. As a regulator, the NHIA is the sole authority that registers, licenses and supervises any health insurance entity in Ghana. Overall, the NHIA is charged with the full implementation of the NHIS, and healthcare providers that seek to offer NHIS services are obliged by law to obtain accreditation from the Authority to safeguard the quality and integrity of their operations. The NHIA is also responsible for prudent management of funds accruing from general revenues and others sources into the National Health Insurance Fund (NHIF). Monies from the NHIF are used to offset the healthcare costs of subscribers and for the broader administration of the Scheme.

Given its broad spectrum, diversity, and complex nature of the governance and administrative framework, the NHIA operates as a decentralized system with offices at the regional and district levels. Services provided by these offices include membership registration, accreditation of service providers, renewal of membership ID cards, management of health claims and provider payments, amongst other activities. As part of measures to boost public confidence, as well as ensure equitable and efficient health service delivery, the NHIA has introduced a diverse range of innovations including a centralized claims processing centre, electronic claims management, clinical audits, capitation, biometric ID health cards, and increased use of information communication technology (NHIA Annual Report, 2013). Under the new NHIS law, three committees namely, (a) Finance and investment Committee (b)

National Health Insurance Oversight Committee; and (c) Private Health Insurance Oversight Committee have also been established to improve the NHIA's efficiency and overall delivery.

Prior to the 2012 amendment of the original NHIA legislation, the district level scheme of the NHIS operated as semi-autonomous entities with their own Boards of Trustees, Scheme Managers, and committees established by the District Assembly for health insurance related matters (Mensah, Oppong, and Schmidt, 2009). In terms of administrative and managerial hierarchy, the NHIA is steered by a Board at the apex. There is a Chief Executive Officer who has responsibility for the day-to-day administration of the entire health financing system, and is answerable to the Board in performance of duties assigned to that position. Below the Chief Executive Officer exists a wide range of staff of various professional and technical background that assist in the effective 
administration of the schemes. These supporting officials include three Deputy Chief Executives, technical directors and deputy directors of multiple directorates and departments. Following from the central tenets embodied by the health insurance arrangement, the NHIA operates with the overall objective of providing protection against financial risk and the cost of quality basic health care for all residents in Ghana (NHIA Annual Report, 2013).

In terms of its operation, the scheme has since its establishment made modest progress in expanding financial access to healthcare for many Ghanaians. The law establishing the health insurance schemes in Ghana made it mandatory for all Ghanaians to subscribe to any of the three tiers, and "a 10-year grace period was stipulated in the law (Act 650) before strict enforcement would start" (Fenny 2017, p. 355). The private and commercial health insurance scheme together had combined subscriber membership of about 144,000 as at the end of 2016. As shown in the figure below, at the end of the same year, the total membership of the NHIS was $11,029,339$, representing about $39 \%$ of the total population of the country. Notwithstanding the overall relative progress made in providing financial access to healthcare, about $60 \%$ of Ghanaians are not covered by any of the three tiers under the NHIA even after more than a decade since the scheme was established. As figure 1 shows, enrolment into the scheme grew at a fast rate within the first five years of its inception and has since hovered around $39 \%$ of the population.

Figure 1: Trends in NHIS Membership from 2005

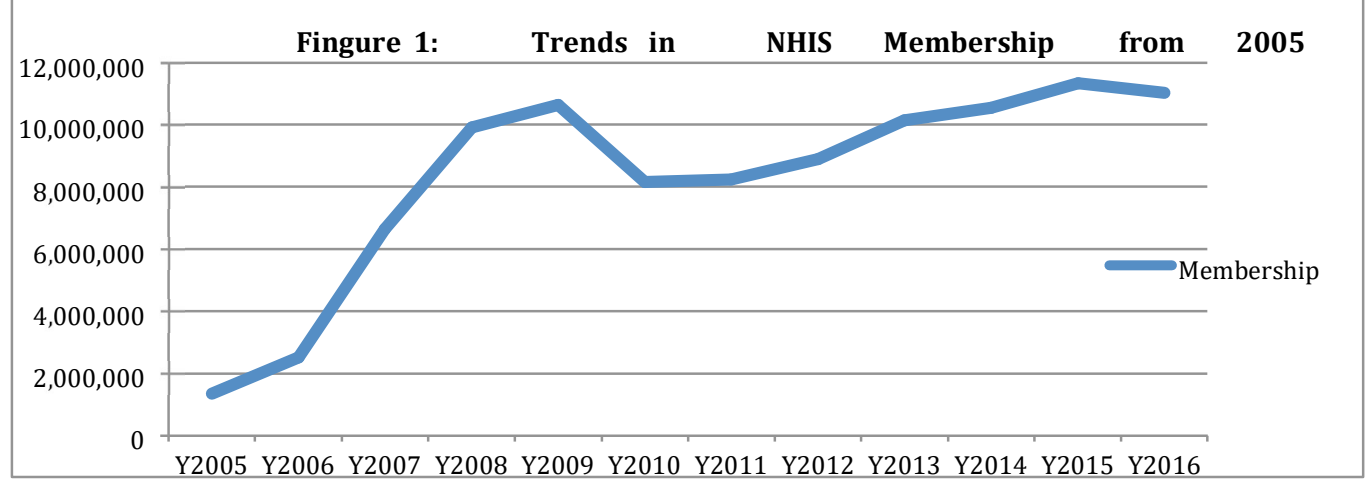

Source: NHIA 2017-the graph is generated from data submitted by the NHIA to the National Development Planning Commission (NDPC) towards the preparation of the 2016 Annual Progress Report.

Subscribers or members of the NHIS are placed in three different categories, and these include persons in the informal sector of the economy who are required to pay an annual premium, formal sector workers who are compelled through compulsory monthly salary deductions of $2.5 \%$, and the exempted category which includes persons under eighteen years of age, persons 70 years and above, pregnant women, and others who for various reasons are described as indigents, all of whom are enrolled into the scheme without any direct cost to the individual. Table 1 below provides a breakdown of the regional distribution of various categories of subscribers to the scheme. Overall, majority of the members or subscribers of the NHIS are in the exempted category and, therefore, access healthcare on account of the NHIS without any premiums. While Ashanti Region has the highest number of the exempted members, Upper West Region has the lowest proportion of exempted NHIS members.

Table 1: Regional breakdown of various categories of NHIS members

\begin{tabular}{|l|l|l|l|l|}
\hline REGION & INFORMAL & EXEMPT & $\begin{array}{l}\text { SSNIT } \\
\text { CONTRIBUTORS }\end{array}$ & TOTAL \\
\hline ASHANTI & 610,085 & $1,444,760$ & 76,731 & $2,131,576$ \\
\hline BRONG AHAFO & 381,627 & 896,716 & 40,171 & $1,318,514$ \\
\hline CENTRAL & 247,845 & 604,039 & 36,149 & 888,033 \\
\hline EASTERN & 425,030 & 867,474 & 60,074 & $1,352,578$ \\
\hline GREATER ACCRA & 581,060 & 892,991 & 121,898 & $1,595,949$ \\
\hline NORTHERN & 226,995 & 863,426 & 17,403 & $1,107,824$ \\
\hline UPPER EAST & 152,587 & 486,224 & 14,483 & 653,294 \\
\hline UPPER WEST & 130,833 & 356,959 & 10,507 & 498,299 \\
\hline VOLTA & 235,110 & 535,990 & 32,521 & 803,621 \\
\hline WESTERN & 325,985 & 628,702 & 36,646 & 991,333 \\
\hline Total & $\mathbf{3 , 3 1 7 , 1 5 7}$ & $\mathbf{7 , 5 7 7 , 2 8 1}$ & $\mathbf{4 4 6 , 5 8 3}$ & $\mathbf{1 1 , 3 4 1 , 0 2 1}$ \\
\hline
\end{tabular}

Note: Informal includes $0.2 \%$ of security services, Exempt excludes SSNIT contributors: Source: National Development Planning Commission (NDPC) 2017

Since coming into force, the NHIA has accredited a number of health service institutions with the view to 
making healthcare accessible to all Ghanaians. Accredited health facilities refer to both public and private sector health service providers at which members or subscribers of the national insurance scheme are permitted to obtain specified services at a cost to the scheme. The increasing number of service providers accredited across the country and the geographical spread is an indication of the growing popularity of the scheme across the country. For instance between 2009 and 2013, the NHIA granted accreditation to a total of 3,822 health service providers. The regional distribution of the number of health service providers accredited in each of the ten regions are illustrated in figure 2 below:

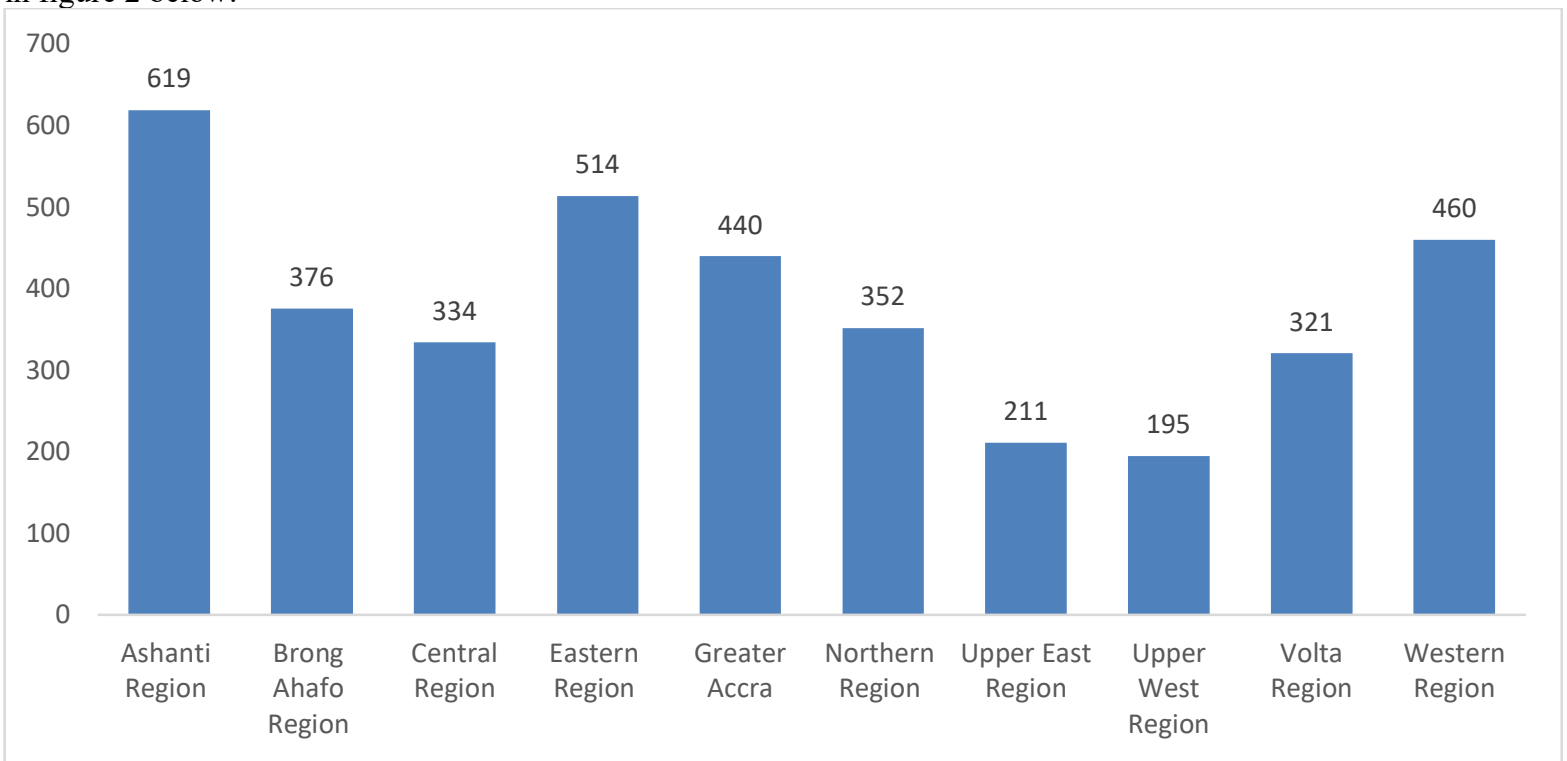

Source: NHIS 2013

As shown in figure 2 above, at the end of 2013, while Ashanti, Eastern, Greater Accra and Western Regions had the highest number of NHIS accredited service providers, Upper East and Upper West regions had the lowest number of NHIS accredited facilities. The remaining regions, which include Brong Ahafo, Central, Northern, and Volta regions had between 321 and 376 NHIS accredited service providers. The NHIS accredited facilities include various institutions that provide services in relation to healthcare such as "Chemical Shops, CHP Zones, Clinics, Dental Clinics, Diagnostic Centres, Eye Clinics, Health Centres, Laboratories, Maternal Homes, Pharmacies, Physiotherapy, Polyclinics, Primary, Secondary and Tertiary Hospitals and Ultrasound" (NHIA, 2013, p. 8). About $54.3 \%$ of the accredited service providers are health facilities wholly owned and operated by the government, while the remaining are either established by religious organizations, private establishments or partially owned by the state. Undoubtedly, the coming into force of the NHIS seems to have revolutionized access to healthcare in Ghana. In particular, as indicated in Figure 3 below, outpatient utilization of health services on account of the NHIS rose from 597,859 visits in 2005 to 26,875,489 in 2016. Similar trends are observed in inpatient utilization, which increased from 28,906 to $1,416,065$ within the same period.

\section{Figure 3: Trends in outpatient and inpatient utilization of NHIS}

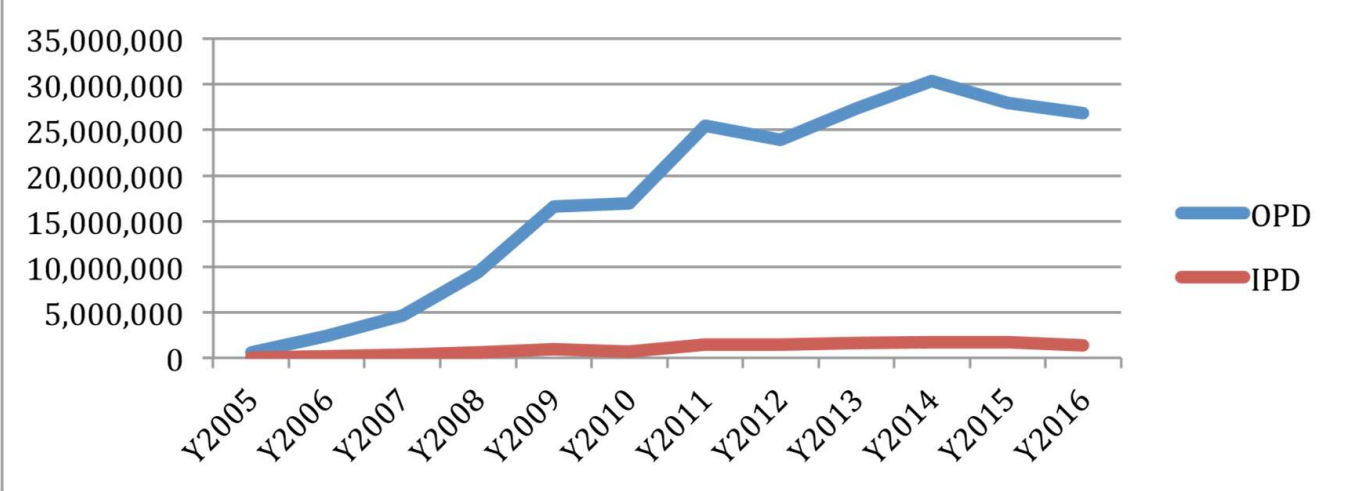

Source: NHIA 2017

Although the annual increase in the number of visits made by NHIS subscribers to the accredited health facilities raises fundamental questions about the overall health status of Ghanaians, particularly against the 
background of poor health seeking behavior imposed by the previous cash-and-carry system, the phenomenon has been narrowly interpreted as "positive because people now visit the hospitals often for their healthcare needs. It reflects improved health seeking behavior and outcomes of Ghanaians" (Republic of Ghana, 2016, p. 29). Research has shown that women enrolled in the NHIS tend to have fewer birth complications and infant deaths (Mensah, Oppong, Bobi-Barimah, Frempong, \& Sabi, 2010). These positive observations arguably stem from the enhanced accessibility to health care, reduction in self-medication, a shift from the delay in hospital visits to earlier diagnosis, and provision of free maternal and child health services under the scheme (all of which embody the substance of citizenship).

Nonetheless, the rising number of visits to health facilities calls for improvement in preventive public health education, which when successfully carried out could lead to a decline in the number of visits to health facilities and save the scheme significant amounts of money to meet demand, while protecting the principles behind resource pooling. Figure 4 below shows the financial claims on the NHIS by health service providers between 2005 and 2014. The NHIA paid a total of 1,073 million Ghana cedis in 2014 compared with 7.6 million Ghana cedis in 2005. The difference of over 14,018 Ghana cedis in payments made by the NHIA to service providers within the same period raises obvious and troubling concerns about the financial sustainability of the scheme if such trends persist.

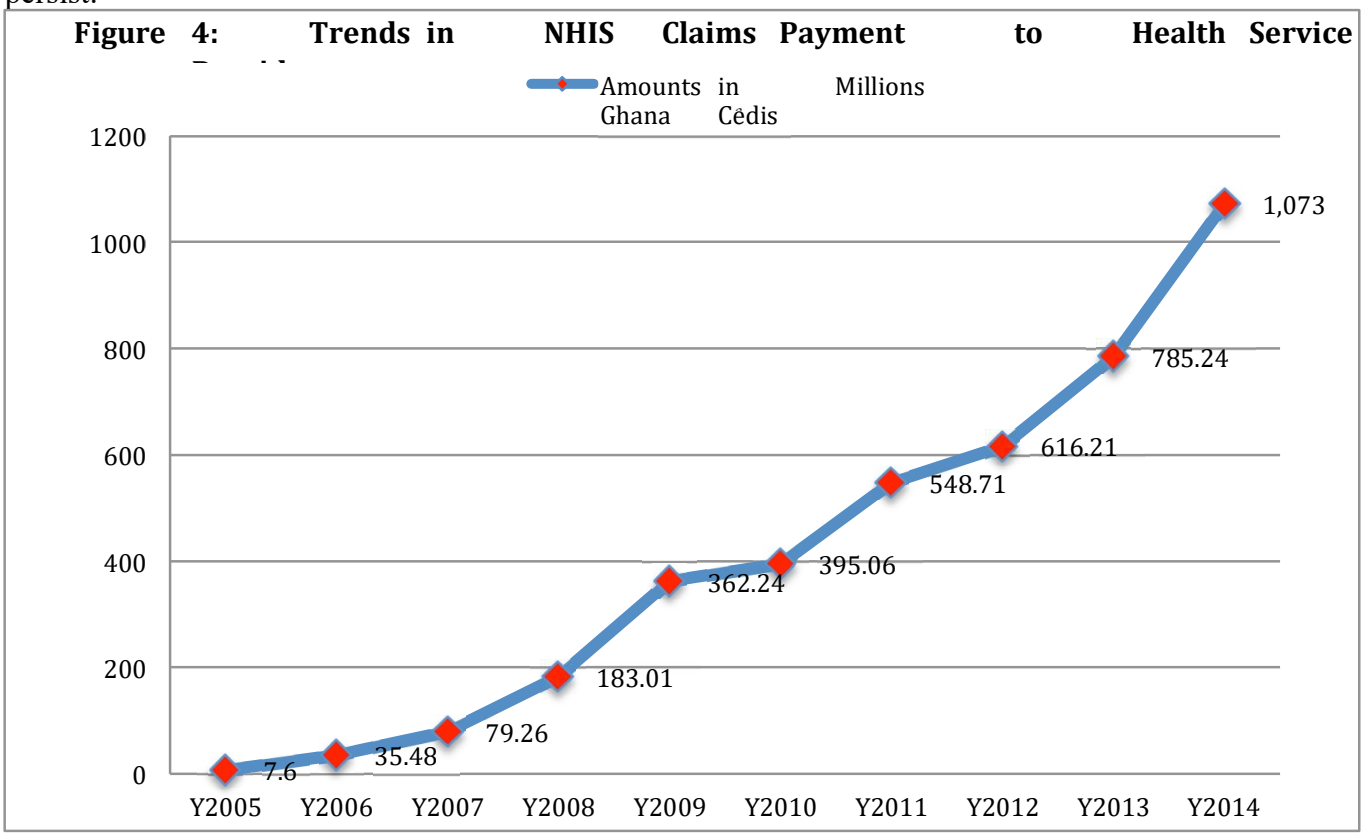

Source: Republic of Ghana, 2016

As figure 4 illustrates, payments by the NHIA for services provided to NHIS subscribers has been on the rise since the scheme replaced the previous cash-and-carry program. While this trend is the result of the growing numbers of people subscribing to the scheme as the primary preference for financing healthcare in Ghana, the rising cost of healthcare is also a major contributory factor for the annual growth in claims made on the scheme by service providers. The rising financial claims on the scheme are also partly attributed to fraudulent claims by some health service providers in connivance with subscribers to the scheme. For instance, a senior management official of the scheme noted that fraudulent claims by service providers, double and over-payments were due to over-invoicing, irregular behaviour of some members of the scheme who hopped from one pharmacy to the other with the same drug prescription to access the same services already obtained elsewhere, among others, as some of the challenges contributing to the growing financial burden on the scheme (Citifmonline, 2015). Clearly, the social constructions and realities observed in the health arena not only point to the complexities of health policy implementation, but also generates important questions concerning reform efforts.

Challenges of the National Health Insurance Scheme

The primary objective of the NHIS has been to eliminate health affordability obstacles by providing financial access to healthcare. Undoubtedly, the NHIS as a first tier has been successful in expanding health coverage to about $40 \%$ of the population within a short period of time. It is not only better than the cash-and-carry health financing arrangement it sought to replace; it also holds the key to providing access to quality healthcare, and has better prospects for equity in health service delivery. However, careful analysis of the scheme reveals a number of 
challenges and design flaws with backward linkage to the operation of the scheme. In terms of the design, the NHIS has a series of inherent challenges that have significant implications for its efficient management as well as sustainability.

First, the element of 'exemption' grafted into the NHIS as an avenue for providing relief and access to those who cannot afford to be members through premium-based subscription, has opened the floodgates for rapid enrolment into the scheme. In a country with high levels of poverty and inequality, this is not surprising. And while the growth in membership of the NHIS is often seen as an achievement, a large majority of over $60 \%$ of this membership is within the exempted category (NHIA, 2015b). This implies that majority of NHIS members make no direct financial contributions to the scheme although they enjoy the same rights and privileges as the monthly and annual premium paying members. By this design, the financial burden associated with the management of the scheme is shifted to the few workers in the formal sector who make monthly contributions through $2.5 \%$ payroll tax deductions, and those in the informal sector who voluntarily subscribe via annual premiums. Of particular interest is that while these exemptions protect the collective entitlement of the vulnerable and less-privileged in the society, at the same time, it draws our attention to how national identities and solidarity affect public policy, as well as raise questions concerning the normative premises of social citizenship and cohesion (Johnson Redden, 2002). The challenge, then, is how to accommodate the financial burden imposed by the exemtptions without sacrificing quality and undermining the values of social citizenship.

A second but related problem is that the design of aspects of the exemption for those classified as indigent does not only provide too much discretion to management in making decisions about who qualifies under this category, but it also opens the entire scheme to abuse and political manipulation. The exemption policy is problematic, especially because Ghana does not have a reliable and comprehensive data system from which to pick citizens who face abject poverty, nor has the country a robust mechanism for identifying the most vulnerable among the population for targeting. As Aryeetey et al. (2013) and Macha et al. (2012) observed, the framing of these criteria makes it extremely difficult if not impossible to identify persons who qualify to merit this exemption. Furthermore, in a country where poverty and inequality remains pervasive despite recent experiences of economic growth, compounded by the challenge where a significant proportion of the population consider themselves unemployed, granting free access to healthcare services under the NHIS implies that several people including even those who can afford to pay annual premiums could hide under the unemployed or poverty criteria to qualify for the indigent exemption. Thus, the way and manner in which these exemptions are designed has the potential to promote free riding and irresponsibility among subscribers. Similarly, the open-ended nature of the indigent clause suggests that politicians seeking to win the support of specific segments of the population could manipulate it to their advantage.

Third, although granting the elderly cohort of the population exemption under the NHIS is instrumental in ensuring elimination of obstacles that could impede their access to health services, again the intuitive design of that very exemption raises a number of concerns surrounding normative ideas about the state-citizenship relationship. For instance, it is only the elderly population that is 70 years and above that qualifies for this exemption. The challenge with this criterion is not only inconsistent with the age of retirement in Ghana (i.e., 60 years); it automatically excludes a significant proportion of the elderly cohort aged 60-69 who constitute the majority of the elderly in the country. Given that majority of Ghanaians are without any formal income support at old age, this segment of the population are likely to be inadvertently excluded from the health insurance scheme due to poor economic circumstances (see for instance, Fenny, 2017; Fenny, Kusi, Asante, \& Arhinful 2016). Fenny (2017) noted that "the most financially vulnerable among those aged 60 to 69 are the least likely to have health insurance coverage" (p. 367). In addition, for a country whose life expectancy is around 67 years, it is disingenuous to peg the age for exemption of the elderly under the NHIS at age 70 due to the possibility that most of the elderly population might not get the services when they most need it nor live long enough to enjoy the free access to healthcare that begins only at 70 years. More importantly, the exemption granted the elderly population does not cover major health challenges such as dementia, trachoma, blindness, cancers, arthritis, stroke, hypertension, heart diseases, diabetes, malignant neoplasm, trachoma and alzheimers that are generally associated with ageing.

Another design challenge of Ghana's health financing arrangement is the parallel operation of the three tiers for the same health services. As discussed earlier, what emerged as the three-tier, and later reduced to two-tier health financing system was an attempt to strike a compromise and accommodate various interests, preferences, and ideas floating around as options for financing healthcare in Ghana. However, designing various financing layers to compete for the same subscribers and for the same services has resulted in a number of challenges. The existing arrangement creates room for duplication and fraud, especially because individuals can subscribe to the NHIS under any of the other two tiers at the same time, and make claims on each one of them for the same services obtained. Although the NHIA tries to clarify this problem by arguing that an individual who subscribes to more than one of the financing schemes reserves the right to choose which one of them to be charged for the services used, in practice, the NHIA has no comprehensive means of tracking duplication arising from subscription to multiple schemes, nor has it any effective strategy of monitoring and evaluating claims submitted by individuals 
to either the private mutual health insurance or private commercial health insurance scheme for which payment has already been made by the NHIS. In addition, because all the three schemes were designed to operate concurrently by competing for subscriptions from the Ghanaian people, the NHIS has by its geographical spread, economies of scale, and other resource capabilities effectively crowded-out the other private providers, leaving them with less than one percent of the market share of subscribed membership (Gajate-Garrido \& Owusua, 2013).

The combined effect of these design flaws is that while the NHIS is celebrated for making modest gains in expanding access to healthcare as well as improving utilization of health services, the reality is that the scheme is financially insolvent and has often been unable to honour its obligation to service providers, let alone doing so on time. The inability of the scheme to promptly make payments to service providers has resulted in threats of rejection and outright rejection of the NHIS membership cards by some of the accredited service providers. Service providers have also been reported to compel NHIS card bearing members to instantly make upfront payment in order to receive healthcare services. For instance, in August 2015, the Health Insurance Service Provider Association of Ghana (HISPAG) took a decision not to treat any patient seeking health services on account of the NHIS card arguing that the NHIS had failed to honour its indebtedness of over 125 million Ghana cedis to its member facilities (Myjoyonline, August 4, 2015). Earlier in July 2014, the Christian Health Association of Ghana (CHAG) took a similar decision on the basis that the inability of the NHIS to pay the facilities had affected their ability to purchase medical supplies to effectively and efficiently take care of patients (Daily Graphic, July 2, 2014). To avoid this kind of situation, some of the well-endowed private hospitals and health facilities in the country have elected not to accept the NHIS subscription for their services and operate purely on the basis of either cash-and-carry or private insurance membership schemes. Perhaps a more troubling concern is the fact that arrears owed service providers continue to accumulate, thus exacerbating the challenges pertaining to the payment of health claims by the NHIA. More recently, HISPAG lamented the perennial delay in claims payment, which had resulted in about 20 months of arrears due its members (Citifmonline, February 13, 2018). Consequently, the scheme is faced with a challenge of how to remain relevant to its objective of ensuring protection of the underserved, especially the poor and vulnerable against financial barriers impeding access to healthcare, while at the same time addressing threats posed to the sustainability of the scheme by inadequate funding and rising cost.

\section{Options for Reform in Lieu of Conclusion}

The challenges of the health financing arrangement presents an opportunity for reforms that address the systemic and operational challenges. Lessons drawn from the operations of the health insurance schemes in Ghana highlight the need to (a) contain cost and (b) increase revenue of the NHIS. The spiralling financial burden of the NHIS is partially a result of its design weaknesses. Although one of the objective of the NHIS is to serve as social insurance scheme that focuses on addressing challenges imposed by poverty on access to healthcare, the category of persons exempted from paying premiums under the NHIS needs to be reviewed for practical considerations, and to ensure the scheme does not become a burden onto itself. For instance, while the premium paying members consisting of adults in the informal sector increased only by 0.7 percentage points, the number of persons in the exempt category including "new exempt group of women seeking maternal healthcare" increased by 7.7 percentage points between 2010 and 2015 from 54.9\% to 62.6\% respectively (Osei-Akoto \& Adamba, 2017, pp. 396-397).

Several options exist for reviewing the exemption policy under the NHIS. For instance, rather than granting exemption to both children and adolescents who constitute about $40 \%$ of the exempt persons, a reviewed exemption policy could consider limiting this exemption to only children between the ages of $0-12$ years and allow younger adults aged 13 to 18 years to be processed on to the scheme on the basis of socio-economic circumstances and means-testing. In addition, given that the elderly population that are unfortunate to suffer major ageing related illness are few and in between, the exemption granted the elderly could also be reviewed and limited to only specific and contextually informed health challenges associated with ageing in order to encourage burden sharing, which is one of the policy goals of the Scheme. Even with the elderly population, it is still possible to design their exemption on the foundation of means-testing to ensure that only those who really need to be supported are granted access to healthcare on account of the NHIS. Taken together, these options for addressing the challenges posed by the exemptions granted under the NHIS will significantly reduce the free rider problem and serve as a cost cutting measure to save the scheme some funds without compromising the social insurance objectives of the scheme. And of course, this does not suggest policy lock-in; the rules governing the exemption policy should be amenable enough to be able to quickly adapt to changing circumstances or realities of the health and fiscal environment.

Another approach to cost containment for the NHIS will be to reduce the number of health services it is designed to accommodate, and dismantle concurrent operation by competition between the NHIS and the other providers. In other words, rather than having the NHIS and embedded tiers compete among themselves, the design of the health financing arrangement could be reconfigured so that the NHIS is made truly mandatory for everybody, takes care of limited basic healthcare needs, while companies and communities operating the other two schemes compete for subscribership for health services outside the NHIS approved list of benefits enjoyable by its members. This arrangement would allow the NHIA to make a strong case for employers and business establishments as 
distinct entities to also make some additional monthly contributions to the national health insurance fund, especially because their employees, and in fact customers, are mandatory beneficiaries of the NHIS. Thus, by reducing the list of health services paid for by the NHIS, the policy will free up space for private health insurance in the areas uncovered by the national scheme, allow individuals some autonomy in making decisions about which types of additional health insurance to purchase as a supplement to the NHIS depending on their healthcare needs, and ultimately eliminate the phenomenon of duplication and fraud presently associated with the existing design of the health financing system.

Another option for improving the financial sustainability of the scheme will be to craft the cost sharing arrangements for specific health services in a manner that will engender individual responsibility and minimize abuse (moral hazards) of the scheme. Co-payment is a cost sharing mechanism that will allow for transfer of a small fraction of costs associated with specific health services obtained by NHIS subscribers to the insured to pay directly to service providers. The economic purpose of the NHIS reduces financial risk of illness for the insured. But the rates of utilization so far anecdotally suggests that some of the insured increase their health care utilization even if not necessary due to the elimination of direct financial barriers. Cost sharing arrangements exist in various forms including deductible, co-insurance or co-payment, and ceiling, all of which may require the insured or some of them to pay a fraction of total cost of services obtained from service providers. When designed properly, a contextually based cost sharing mechanism could contain the moral hazards associated with utilization of health care, while enabling the NHIS to control the cost of health insurance without compromising the social purpose of the scheme.

The NHIS needs to be futuristic in its outlook and operations. For instance, the NHIS can diversify the nature of its operations beyond addressing only the financial costs associated with the curative aspect of health care. Investing in well-planned and empirically informed preventive public education campaigns targeted at behavioural change could help to minimize the incidence of ill health among the population and, by extension, save the scheme some much-needed funds. The poor sanitary conditions surrounding most food services across the country, for instance, is a crucial area worthy of attention, especially as food-related ailments hold the potential to exact considerable financial burden on the NHIS. It also makes sense for the NHIA to take advantage of modern technology and other avenues of public education to reach out to inform and share available scientific knowledge about life style patterns that have overall positive linkage to good health, as well as the everyday little and takenfor- granted living habits that have implications for individual health. One way to undertake this public health campaign, especially in the rural areas, is to take advantage of the country's existing national service (youth service) program, to deploy trained and well-motivated national service personnel to every community on a regular basis to meet with the people to share new information, best living and life style practices that promote and minimize the incidence of diseases. Aside public education and sensitization, it is also imperative for the government to strengthen and enforce lax regulatory standards pertaining particularly to the operations of the proliferative food industry. When adopted, the above measure could limit the costs faced by the scheme without comprimsing its original intent.

Finally, it is equally important to move beyond politicization of the NHIS by governments, as well as open up new avenues for the flow of revenue to the scheme without necessarily increasing existing premiums and the national health insurance levy. Against this backdrop, it is imperative to rethink the continued deposit of insurance payments into the Consolidated Fund, and to devise mechanisms that allow for the direct transfer of the National Health Insurance Levy (NHIL) to the NHIL account. Such an approach could help to address the current practice of using NHIA funds for other purposes, and in some respects, allow for a more effective mechanism of resource distribution and payment of health claims. That being said, given the effects of use of both tobacco and alcohol on human health, it is worth introducing a new and higher tax regime on the purchase of these items to support the financial operations of the scheme. Such taxation could prove instrumental in shaping consumer behaviour regarding these items and, in turn, minimize any adverse effects associated with consumption of these items on the healthcare system. All in all, Ghana's NHIS as a social policy experiment is fraught with tension and dilemmas to which there is no easy solution, and formulating appropriate financial reform strategies requires a proper understanding of how national identities interact with ideational, political and institutional forces to inform policy development.

\section{References}

Agyepong, I. A., \& Adjei, S. (2008). Public social policy development and implementation: a case study of the Ghana National Health Insurance scheme. Health policy and planning, 23(2), 150-160.

Aryeetey, G. C., Jehu-Appiah, C., Kotoh, A. M., Spaan, E., Arhinful, D. K., Baltussen, R., \& Agyepong, I. A. (2013). Community concepts of poverty: an application to premium exemptions in Ghana's National Health Insurance Scheme. Globalization and health, 9(1), 12.

Asenso-Okyere, W. K. (1995). Financing health care in Ghana. Retrieved from http://apps.who.int/iris/bitstream/10665/48825/1/WHF_1995_16(1)_p86-91.pdf 
Asenso-Okyere, W. K., Anum, A., Osei-Akoto, I., \& Adukonu, A. (1998). Cost recovery in Ghana: Are there any changes in health care seeking behaviour? Health policy and planning, 13(2), 181-188.

Asenso-Okyere, W. K., Osei-Akoto, I., Anum, A., \& Adukonu, A. (1999). The behaviour of health workers in an era of cost sharing: Ghana's drug cash and carry system. Tropical Medicine \& International Health, 4(8), 586593.

Atim, C., Grey, S., Apoya, P., Anie, S. J., \& Aikins, M. (2001). A survey of health financing schemes in Ghana. Bethesda, Md. Partners for Health Reform, Abt Associates.

Beland, D., \& Cox, R. H. (2011). Ideas and Politics. In D. Beland \& R. H. Cox (Eds.), Ideas and Politics in Social Science Research. New York: Oxford University Press.

Béland, D., \& Ridde, V. (2016). Ideas and Policy Implementation: Understanding the Resistance against Free Health Care in Africa. Global Health Governance, 10(3), 9-23.

Béland, D., Foli, R., \& Kpessa-Whyte, M. (2018). Social Policy as Nation-Building:

Identity Formation, Policy Feedback, and Social Citizenship in Ghana. Canadian Journal of African Studies, 118.

Blanchet, N. J., Fink, G., \& Osei-Akoto, I. (2012). The effect of Ghana's National Health Insurance Scheme on health care utilisation. Ghana medical journal, 46(2), 76-84.

Boafo-Arthur, K. (1999). Ghana: Structural adjustment, democratization, and the politics of continuity. African Studies Review, 42(2), 41-72.

Campbell, J. L. (2002). Ideas, Politics, and Public Policy. Annual Review of Sociology, 28, 21-38.

Carbone, G. (2011). Democratic demands and social policies: The politics of health reform in Ghana. Journal of Modern African Studies, 49(3), 381-408.

Citifmonline (2015). Fraudulent activities hamper our services. Retrieved from http://citifmonline.com/2015/08/28/fraudulent-activities-hamper-our-servicesnhis/

Citifmonline (2018) HISPAG threatens to go back to 'cash and carry' system. Retrieved from http://citifmonline.com/2018/02/13/hispag-threatens-to-go-backto-cash-and-carry-system/

Daily Graphic (2014). Cash \& carry is back as mission hospitals reject NHIS cards from July 2. Retrieved from https://www.graphic.com.gh/news/generalnews/cash-carry-is-back-as-mission-hospitals-reject-nhis-cardsfrom-july-2.html

Fenny, A. P., Kusi, A., Arhinful, D. K., \& Asante, F. A. (2016). Factors contributing to low uptake and renewal of health insurance: a qualitative study in Ghana. Global Health Research and Policy, 1(1), 18.

Fenny, A. P. (2017). Live to 70 Years and over or suffer in silence: Understanding health insurance status among the elderly under the NHIS in Ghana. Journal of Aging \& Social Policy, 29(4), 352-370.

Fischer, F. (2003). Reframing Public Policy: Discursive Politics and Deliberative Practices. United Kingdom: Oxford University Press.

Gajate-Garrido, G., \& Owusua, R. (2013). The national health insurance scheme in Ghana: Implementation challenges and proposed solutions. IFPRI Discussion Paper 01309. Retrieved from https://papers.ssrn.com/sol3/papers.cfm?abstract_id=2373242

Heyen-Perschon, J. (2005). Report on current situation in the health sector of Ghana and possible roles for appropriate transport technology and transport related communication interventions. Institute for Transportation and Development Policy, ITDP.

Johnson Redden, C. (2002). Health as Citizenship Narrative. Polity, 34(3), 355-370.

Konadu-Agyemang, K. (Ed.). (2001). IMF and World Bank sponsored structural adjustment programs in Africa: Ghana's experience, 1983-1999. Ashgate Publishing Limited.

Konadu-Agyemang, K., \& Takyi, B. K. (2001). Structural adjustment programs and the political economy of development and underdevelopment in Ghana. In Konadu-Agyemang, K, IMF and World Bank sponsored structural adjustment programs in Africa: Ghana's Experience, 1983-1999. Aldershot: Ashgate Publishing Limited.

Kpessa-Whyte, M. (2018) "A Comparative Analysis of the Politics of Healthcare Financing Reforms in Ghana in the Rawlings and Kufuor Years", Ghana Journal Social Sciences, Volume 15, Number 1, pp. 1-29

Kusi-Ampofo, O., Church, J., Conteh, C., \& Heinmiller, B. T. (2015). Resistance \& change: A multiple streams approach to understanding health policy making in Ghana. Journal of Health Politics, Policy and Law, 40(1).

Macha J., et al. (2012) "Factors influencing the burden of health care financing and the distribution of health care benefits in Ghana, Tanzania and South Africa", Health Policy and Planning, no. 27, pp. i46-i54.

Mehta, J. (2011). The Varied Roles of Ideas in Politics: From "Whether" to "How". In D. Beland \& R. H. Cox (Eds.), Ideas and Politics in Social Science Research. New York: Oxford University Press, Inc.

Mensah, J. (2011), The Impact of National Health Insurance on Health delivery in Brong Ahafo Region: A Case Study of Jaman North, Thesis Submitted to the Institute of Distance Learning, Kwame Nkrumah University of Science and Technology, Kumasi.

Mensah, J., Oppong, J. R., \& Schmidt, C. M. (2009). Ghana's National Health Insurance Scheme in the context of 
the health MDGs-an empirical evaluation using propensity score matching (No. 157). Ruhr economic papers.

Mensah, J., Oppong, J. R., Bobi-Barimah, K., Frempong, G., \& Sabi, W. (2010). An evaluation of the Ghana National Health Insurance scheme in the context of the health MDG's. (The Human Science Resource Council: Commissioned by the Global Development Network (GDN)).

Myjoyonline (2015). Private hospitals in Kumasi demand cash from NHIS card holders. Retrieved from https://www.myjoyonline.com/news/2015/August4th/private-hospitals-in-kumasi-demand-cash-from-nhiscard-holders.php

National Development Planning Commission (2017), 2016 Annual Progress Report on the Implementation of the Ghana Shared Growth and Development Agenda (GSGDA) II, Republic of Ghana, Accra

NHIA Annual Report (2013). Accra, Ghana: National Health Insurance Authority. http://www.nhis.gov.gh/files/2013\%20Annual\%20Report-Final\%20ver\%2029.09.14.pdf

National Health Insurance Regulations (2004) - L.I. 1809. Republic of Ghana.

NHIA (2012). National Health Insurance Act (Act 852). Republic of Ghana.

NHIA (2015). Guidelines for Private Health Insurance Schemes in Ghana. National Health Insurance Authority. Ghana. Retrieved from http://www.nhis.gov.gh/files/PHISREVISEDGUIDELINES.pdf

NHIA (2015b), Strategic Plan for the National Health Insurance Authority 2015,2018, Republic of Ghana, Accra

NHIA (2017)-Additional Data from the National Health Insurance Authority submitted to the National Development Planning Commission (NDPC) towards the preparation of the 2016 Annual Progress Report, Accra

NPP Manifesto (1996). Development in freedom, agenda for change. Accra: New Patriotic Party.

Nyonator, F., \& Kutzin, J. (1999). Health for Some? The Effects of User Fees in the Volta Region of Ghana. Health Policy and Planning, 14(4), 329-341.

Oppong, J. R. (2001). Structural adjustment and the health care system. In Konadu-

Agyemang, K, IMF and World Bank sponsored structural adjustment programs in Africa: Ghana's Experience, 1983-1999. Aldershot: Ashgate Publishing Limited.

Osei-Akoto, I., \& Adamba, C. (2017). Social health insurance in Ghana. The economy of Ghana sixty years after independence, 385.

Rawlings, J. J. (1997) "State of the Nation Address" in State of the Nation: A Compendium of Presidential State of the Nation Addresses in Ghana's $4^{\text {th }}$ Republic (1993-2013) compiled in 2013 by Kwaku Amoabeng Ortsin, Unishere Publication, Accra

Republic of Ghana (2016), Accounting to the People, Government of Ghana, Accra

Ridde, V. (2009). Policy Implementation in an African State: An Extension of Kingdon's Multiple-Streams Approach. Public Administration, 87(4), 938-954.

Sabi, W. K. (2005). Mandatory community-based health insurance schemes in Ghana: prospects and challenges (Doctoral dissertation, University of Cape Town).

Seddoh, A., Adjei, S., \& Nazzar, A. (2011). Ghana's National Health Insurance Scheme: Views on progress, observations, and commentary. Accra, Ghana: Centre for Health and Social Services, 20.

Seddoh, A., \& Akor, S. A. (2012). Policy initiation and political levers in health policy: Lessons from Ghana's health insurance. BMC Public Health, 12(1), S10.

Sen A. K. (1999), Health in Development" in Bulletin of the World Health Organization, vol. 77, no. 8, pp-619623

Sen A. K. (2002), "Why Health Equity" in Health Economics, vol. 11, pp. 659-666.

Schmidt, V. A. (2008). Discursive Institutionalism: The Explanatory Power of Ideas and Discourse. Annual Review of Political Science, 11, 303-326.

Schofield, J. (2001). Time for a Revival? Public Policy Implementation: A Review of the Literature and an Agenda for Future Research. International Journal of Management Reviews, 3(3), 245-263.

Singleton, J. (2006). Negotiating change: An analysis of the origins of Ghana's National Health Insurance Act. Retrieved from http://digitalcommons.macalester.edu/soci_honors/4

Sulzbach, S., Garshong, B., \& Owusu-Banahene, G. (2005). Evaluating the effects of the national health insurance act in Ghana: Baseline report. Partners for Health Reformplus.

Wahab, H. (2008). Universal healthcare coverage: assessing the implementation of

Ghana's NHIS law'. In Workshop in Political Theory and Policy Analysis MiniConference, Bloomington, IN: Indiana University.

Witter, S., \& Garshong, B. (2009). Something old or something new? Social health insurance in Ghana. BMC International health and human rights, 9(1), 20. 